\title{
THE CHALLENGE OF DIAGNOSING VERTICAL ROOT FRACTURE: A CASE REPORT
}

\author{
Dania F. Bogari*
}

\begin{abstract}
Diagnosing a vertical root fracture has been a challenge for both general dentists and endodontists. In this report, we emphasize the importance of obtaining radiographs from three angulations to aid in the diagnosis of vertical root fracture. This step is an easy and cost-effective way to give the clinician a three-dimensional image of the tooth anatomy/morphology and etiology and will hopefully aid in obtaining the correct diagnosis and treatment plan.
\end{abstract}

KEYWORDS: Vertical root facture, VRF, Diagnosis, Case report

\section{INTRODUCTION}

One major complication after a root canal treatment (RCT) is vertical tooth fracture (VRF). In the literature, the incidence of extraction as a result of root fracture can vary from $4.4 \%$ to $67 \%{ }^{(1-4)}$. Thus, studies have shown that full coverage after RCT is mandatory for greater tooth life ${ }^{(5,6)}$. A VRF diagnosis in the clinic has been a challenging task for dentists regardless of the advances in technologies for such diagnoses; therefore, cone beam computer tomography (CBCT) was introduced to overcome the limitations of the traditional two-dimensional periapical radiographs, although evidence of this remains controversial ${ }^{(6-8)}$. Therefore, it is always important to attend to each detail and gather all the necessary historical information, obtain proper and necessary radiographs, and perform essential diagnostic tests to aid in the accurate definite diagnosis. A dentist's knowledge and experience with such cases will always weigh toward reaching a proper diagnosis and providing the best treatment options to patients.

\section{Case Report}

A 28-year-old female presented to our clinic with a chief complaint, "I feel pain on my tooth when I bite on it.". Past medical history was non-significant, and the patient mentioned a history of RCT for the tooth that was done more than 6 years ago. She also mentioned that antibiotics were prescribed by general dentists several times within the prior two months since the pain started, which used to come and go but is now getting worse.

A panoramic radiograph was taken as part of a routine dental consultation to give the patient a complete concept of the dental treatments necessary,

\footnotetext{
* Department of Endodontics, Faculty of Dentistry, King Abdulaziz University, Jeddah, Saudi Arabia.
} 
regardless the chief complaint. The panoramic radiograph showed congenitally missing wisdom teeth, old amalgam fillings, large recurrent caries under one of the molars, and one RCT with a full coverage crown (Figure 1). On examination, no abnormal oral soft tissues were found. Pain occurred with percussion and palpation and also when biting on a tooth sloth, particularly at the meso-lingual cusp of tooth \#46 (no. 30). The full-coverage crown was bulky in shape with open margins in some areas. As part of our routine, any tooth undergoing $\mathrm{RCT}$ is radiographed from three periapical angles (Figure 2). The view from the mesial angle (Figure 2B) showed a clear VRF of the mesial root; this is unclear in the views from the straight and distal angles (Figures 2A \& C). Furthermore, a "J"shaped or halo type bony defect was seen in both the straight and mesial shift radiographs (Figures $2 \mathrm{~A} \& \mathrm{~B}$ ) but not in the distally-angled view (Figure 2C). No deep pockets were seen around the tooth; pocket depths ranged from 2 to $3 \mathrm{~mm}$ at all sites. Mobility was also not detected. At this point, the endodontic diagnosis was symptomatic apical periodontitis. After gathering all the necessary information and discussing the case with the patient, VRF was expected on that tooth, and the prognosis was hopeless. Extraction and replacement with an implant was the suggested treatment plan. The patient was hesitant to undergo an exploratory surgical process to confirm the diagnosis. Instead, she agreed that we remove the crown and visualize the fracture under a dental microscope so that she would feel more comfortable with the treatment plan, because she had invested a considerable amount of money to save the tooth. Under local anesthetic (2\% lidocaine and 1:100 k epinephrine) the crown was removed (Figure 3), and a rubber dam was placed. Once the core was removed, the crack line was clearly observed (Figure 4). Once the gutta percha was exposed coronally from the canals using a heated system-B tip, blood started filling the canals. The patient, who was able to visualize the situation via an intraoral camera, accepted the option to be immediately referred to an oral surgeon for extraction. The tooth came out in several pieces, but without a traumatic experience for the patient.

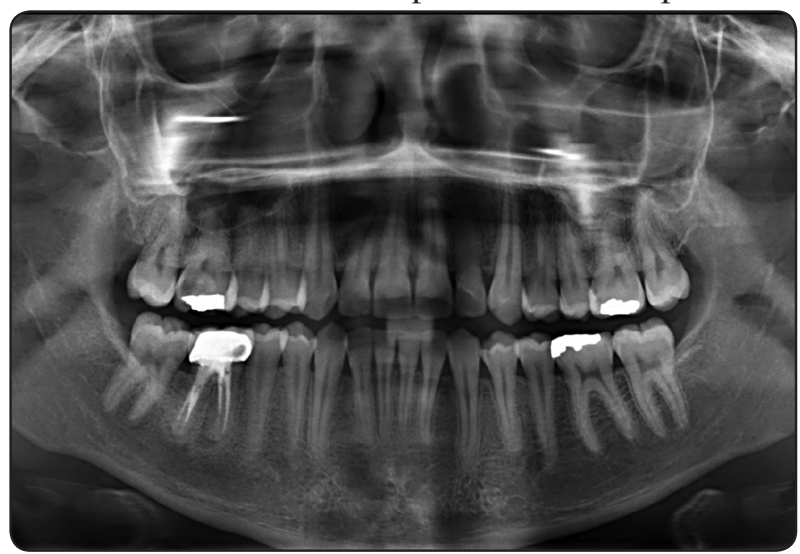

Fig. (1) A panoramic radiograph comprehensively shows the dental problems of the patient, including the presence of periapical radiolucency under the lower right 1 st molar tooth \#46 (no. 30).

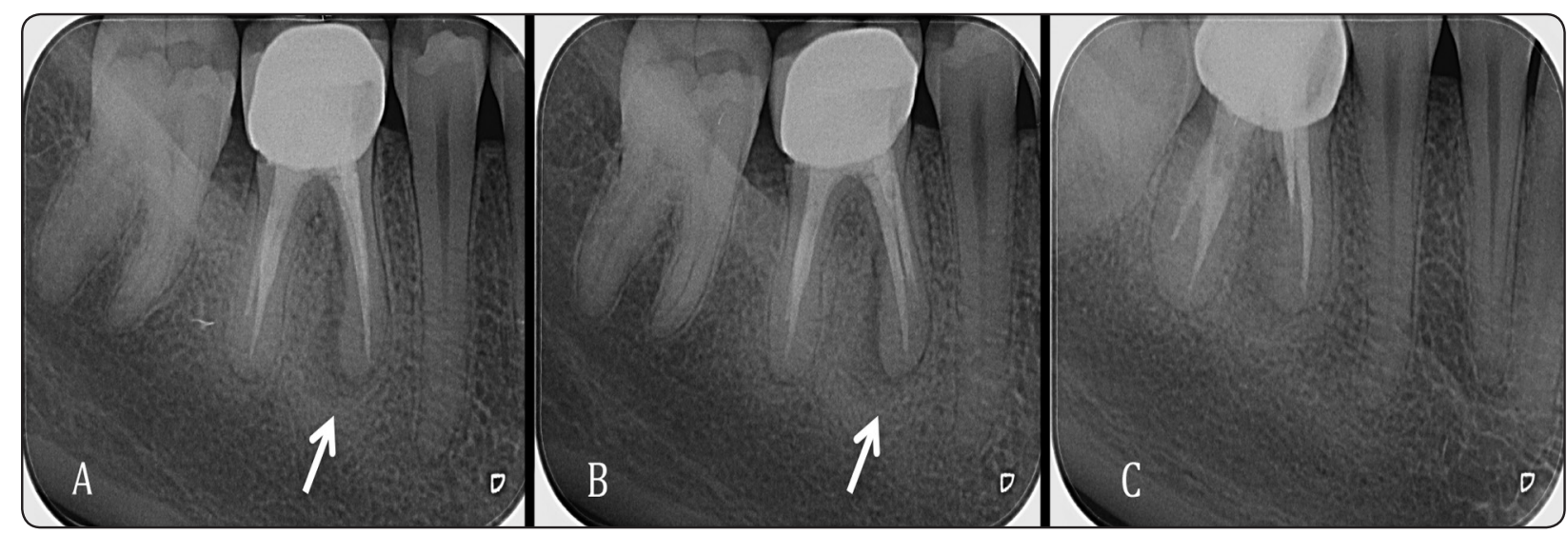

Fig. (2) Periapical radiographs from the (A) straight angle, (B) mesial angle, and (C) distal angle. The "J"-shaped or halo-type radiolucency indicates the presence of a vertical root fracture (arrow). 


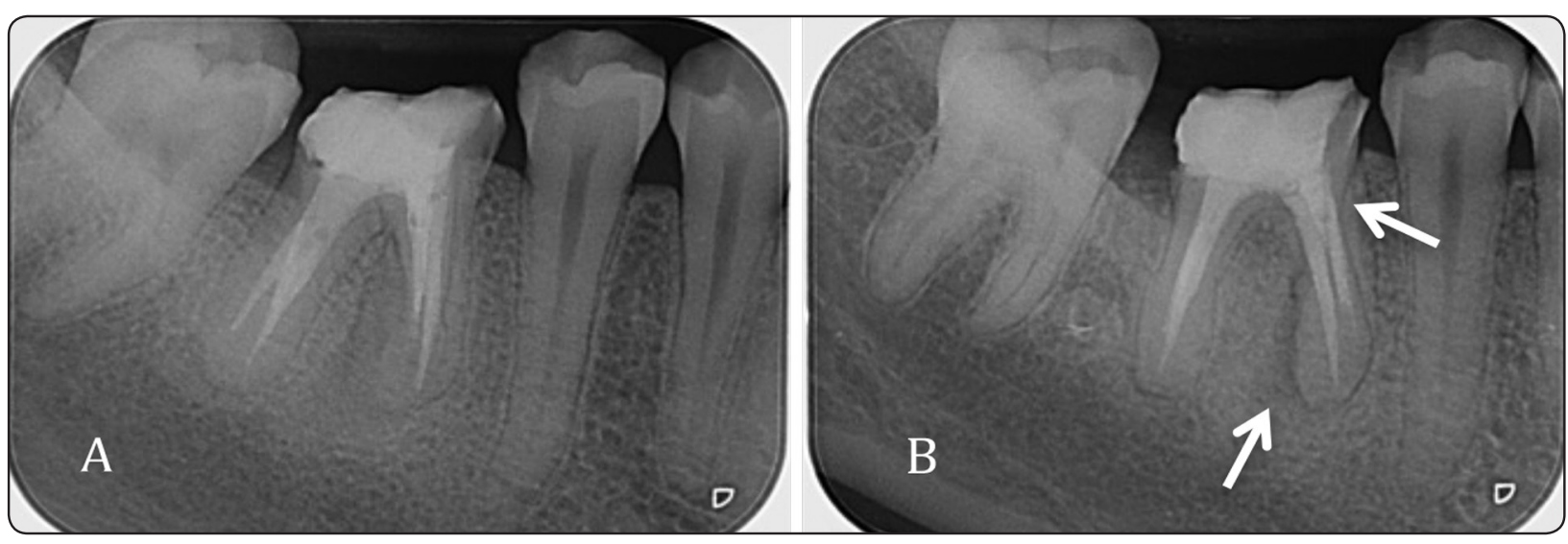

Fig. (3) After removing the defective crown, periapical radiographs were taken from a (A) straight angle and (B) mesial angle. The "J"-shaped or halo-type radiolucency indicates the presence of a vertical root fracture (arrow), and also the fracture line is clear in that angle (arrow).

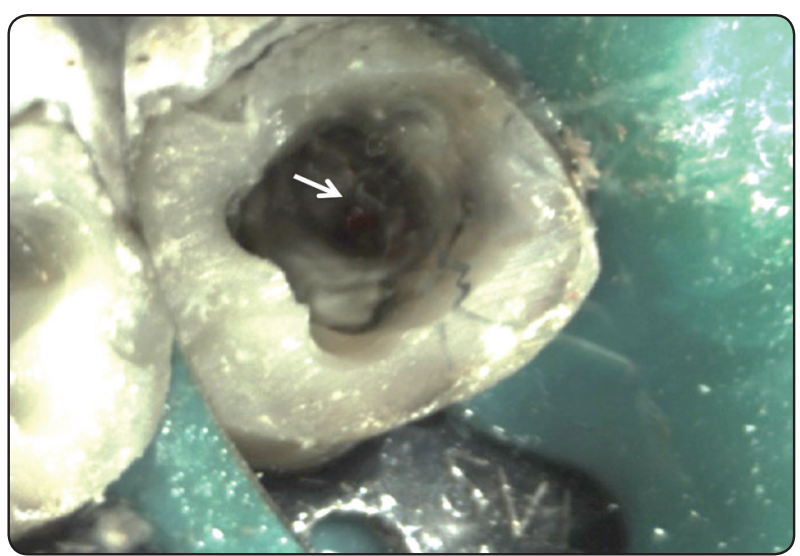

Fig. (4) A clinical picture showing the starting point of the fracture line (arrow)

\section{DISCUSSION}

A VRF diagnosis is challenging for both general dentists and endodontists. Several predisposing factors must be considered for teeth that have received RCT and include root canal anatomy, morphology, and remaining dentin ${ }^{(9,10)}$. In this case, it was clear from the angulated radiographs that the root morphology of the mesial root differed from the norm. In addition, the short filling of the mesiolingual canal indicated difficulties encountered by the previous endodontist during canal preparation, as per a conversation with the patient. These factors could have contributed, at least in part, to the VRF. The sudden pain on biting occurring on a RCT tooth after more than
5 years of treatment, the "J"-shaped or halo-type of radiolucency seen in the periapical radiographs during examination, and the pain on percussion and palpation all raised red flags supporting a VRF diagnosis. These findings agree with other reports ${ }^{(11,12)}$. However, we can clearly see that the VRF was evidenced only in the mesial angulated radiograph and not on others. If a dentist followed a protocol of specifying only one radiograph, this important piece of information could easily have been missed. This is why the American Association of Endodontists recommend the use of "at least two new periapical radiographs" during the diagnostic step. ${ }^{13}$ Such an approach overcomes the limitations of two-dimensional radiography and gives a threedimensional sense to the situation. Some studies support the use of CBCT to overcome this issue and confirm a VRF diagnosis that cannot be confirmed clinically ${ }^{(14,15)}$. However, this remains an area of controversy. The accuracy and usefulness of CBCT in diagnosing VRF, particularly in endodonticallytreated teeth, can depend on several factors such as machine settings, fracture direction, and the experience of the dentist ${ }^{(7)}$. In addition, because of the cost of obtaining such technology, or adding it to the treatment cost, which most insurance companies do not cover, will limit its use. Thus, taking three radiographs from different angles is one simple way to aid the diagnosis of VRF. In the present case, the patient refused to undergo exploratory surgery to 
confirm diagnosis, as seen with other patients ${ }^{(16)}$, and she leaned toward a less aggressive approach of removing the crown and probing inside the tooth, as a conventional means of visualizing and confirming diagnosis under a dental microscope.

\section{CONCLUSION}

Vertical root fracture is a common concern after RCT. Its diagnosis is challenging and requires knowledge and awareness of the dentist, who must carefully gather all the necessary information to reach a definite diagnosis. Obtaining three radiographs at different angles is an easy and cost-effective way to give the clinician a three-dimensional image of the tooth anatomy/morphology and etiology, hopefully aiding in the correct diagnosis and treatment plan. Thus, we recommend this approach as a standard of care in all cases where RCT is applied.

\section{Patient Consent Form}

A consent form was obtained from this patient authorizing the release of her information and radiographs for publication and education purposes.

\section{ACKNOWLEDGEMENT}

None.

\section{DISCLOSURE}

The author declares no conflict of interest.

\section{REFERENCES}

1. Toure B, Faye B, Kane AW, Lo CM, Niang B, Boucher Y. Analysis of reasons for extraction of endodontically treated teeth: a prospective study. J Endod. 2011;37(11):1512-5.

2. Chrysanthakopoulos NA. Reasons for extraction of permanent teeth in Greece: a five-year follow-up study. Int Dent J. 2011;61(1):19-24.

3. Byahatti SM, Ingafou MS. Reasons for extraction in a group of Libyan patients. Int Dent J. 2011;61(4):199-203.

4. Axelsson P, Nystrom B, Lindhe J. The long-term effect of a plaque control program on tooth mortality, caries and periodontal disease in adults. Results after 30 years of maintenance. J Clin Periodontol. 2004;31(9):749-57.

5. Salehrabi R, Rotstein I. Endodontic treatment outcomes in a large patient population in the USA: an epidemiological study. J Endod. 2004;30(12):846-50.

6. Corbella S, Del Fabbro M, Tamse A, Rosen E, Tsesis I, Taschieri S. Cone beam computed tomography for the diagnosis of vertical root fractures: a systematic review of the literature and meta-analysis. Oral Surg Oral Med Oral Pathol Oral Radiol. 2014;118(5):593-602.

7. Baageel TM, Allah EH, Bakalka GT, et al. Vertical root fracture: Biological effects and accuracy of diagnostic imaging methods. J Int Soc Prev Community Dent. 2016;6(Suppl 2):S93-S104.

8. Takeshita WM, Iwaki LC, da Silva MC, Sabio S, Albino PR. Comparison of periapical radiography with cone beam computed tomography in the diagnosis of vertical root fractures in teeth with metallic post. J Conserv Dent. 2014;17(3):225-9.

9. Chai H, Tamse A. The Effect of Isthmus on Vertical Root Fracture in Endodontically Treated Teeth. J Endod. 2015;41(9):1515-9.

10. Prithviraj DR, Bhalla HK, Vashisht R, Regish KM, Suresh P. An overview of management of root fractures. Kathmandu Univ Med J. 2014;12(47):222-30.

11. PradeepKumar AR, Shemesh $H$, Jothilatha $S$, Vijayabharathi R, Jayalakshmi S, Kishen A. Diagnosis of Vertical Root Fractures in Restored Endodontically Treated Teeth: A Time-dependent Retrospective Cohort Study. J Endod. 2016;42(8):1175-80.

12. Tsesis I, Rosen E, Tamse A, Taschieri S, Kfir A. Diagnosis of vertical root fractures in endodontically treated teeth based on clinical and radiographic indices: a systematic review. J Endod. 2010;36(9):1455-8.

13. http://www.aae.org. Accessed 11-20-2017.

14. Zou X, Liu D, Yue L, Wu M. The ability of cone-beam computerized tomography to detect vertical root fractures in endodontically treated and nonendodontically treated teeth: a report of 3 cases. Oral Surg Oral Med Oral Pathol Oral Radiol Endod. 2011;111(6):797-801.

15. Hassan B, Metska ME, Ozok AR, van der Stelt P, Wesselink PR. Detection of vertical root fractures in endodontically treated teeth by a cone beam computed tomography scan. J Endod. 2009;35(5):719-22.

16. Walton RE. Vertical root fracture: Factors related to identification. J Am Dent Assoc. 2017; 148(2):100-105. 